\title{
COMUNIDADES POSTHUMANISTAS: DOS EJEMPLOS DE VÍNCULOS NO ESPECISTAS ENTRE CANES Y ANIMALES HUMANOS EN LA LITERATURA Y EN EL CINE LATINOAMERICANOS
}

Posthuman communities: TWO EXAMPLES OF NON-SPECIESIST LINKS BETWEEN HUMAN ANIMALS AND DOGS IN LATIN-AMERICAN LITERATURE AND FILM

Paula Fleisner

Universidad de Buenos Aires Buenos Aires - Argentina

\section{Resumen}

En este trabajo ofreceré, a propósito del film La mujer de los perros (2015) de Laura Citarella y Verónica Linás y de la novela Perros héroes. Tratado sobre el futuro de América Latina visto a través de un hombre inmóvil y sus treinta Pastor Belga Malinois (2005) de Mario Bellatin, una posible contribución a los "estudios animales" en general y a los "estudios perrológicos" en particular, desde una perspectiva materialista posthumana en la búsqueda de un pensamiento de la materialidad animal excedente de cualquier metáfora humana. De este modo, contextualizaré inicialmente el materialismo posthumano en el marco (parergon) de los Animal Studies para poder dar cuenta luego de algunos elementos del film que conj(et)uran modos no jerárquicos y físicos de cercanía inter-especies y de la novela que permiten pensar más allá de una consideración simbolista, una sintomatología perruna.

Palabras claves: comunidad, animalidad, humanidad, posthumanismo.

\section{Abstract}

With regard to the film La mujer de los perros (2015) by Laura Citarella and Verónica Linás and the novel Perros héroes. Tratado sobre el futuro de América Latina visto a través de un hombre inmóvil y sus treinta Pastor Belga Malinois (2005) by Mario Bellatin, I will offer a possible contribution to "animal studies" in general and to "dogological studies" in particular, from a posthuman materialist perspective, seeking a conception of animal materiality beyond any human metaphor. Thus, to begin with, I will

\section{Resumo}

Neste trabalho, vou oferecer, no que diz respeito ao filme La mujer de los perros (2015), de Laura Citarella e Verónica Linás, e ao romance Perros héroes. Tratado sobre el futuro de América Latina visto a través de un hombre inmóvil y sus treinta Pastor Belga Malinois (2005), de Mario Bellatin, uma possível contribuição para os "estudos animais" em geral e para "estudos cachorrológicos" em particular, de uma perspectiva materialista póshumana, na busca de um pensamento de materialidade animal, superando 
contextualize posthuman materialism in the framework (parergon) of Animal Studies to be able to account for certain elements in the film that venture a guess into non-hierarchical and physical modes of inter-species closeness, as well as elements in the novel that allow us to think beyond a symbolist consideration: a canine symptomatology.

Keywords: community, animality, humanity, posthumanism. qualquer metáfora humana. Desta forma, contextualizarei inicialmente o materialismo pós-humano no quadro (parergon) dos Animal Studies para poder explicar alguns elementos a) do filme que conjecturam modos não hierárquicos $\mathrm{e}$ físicos de proximidade inter-espécies e b) do romance que nos permitem pensar, além de uma consideração simbolista, uma sintomatologia canina.

Palavras-chave: comunidade, animalidade, humanidade, póshumanismo.

El arte ha sido pionero en encontrar modos de imaginar mundos perceptivos no humanos y modos de vinculación entre lo existente que no remitan necesariamente a la jerarquización impuesta por el humanismo antropocéntrico. En lo que respecta a la así llamada "cuestión animal" se ha podido afirmar que el arte lleva una gran ventaja sobre la filosofía, pues no fue necesario esperar a fines del siglo pasado para encontrar formas disidentes del relato y la figuración del fondo revuelto indefinido y como indiferente de la diferencia de lo existente (FOUCAULT, 1984: 9).

Sin embargo, en relación con los perros -esos seres imposibles, híbridos de materia animal y técnica- la literatura y el cine contemporáneos han sucumbido mayormente a una figuración representacional que busca cumplir con el objetivo de devolver "seguridad" a la subjetividad extraviada en la actual hostilidad del mundo global. Pero no sólo el contenido artístico es humanista, sino que el dispositivo representacional y simbólico es, a su vez, en sí mismo especista, en la medida en que necesariamente implica la perspectiva de un sujeto de la representación, cuya "identidad personal" será inventada, sostenida y/o deconstruida en el discurrir de la obra. Este sujeto en torno al cual se ordenan historias y montajes es siempre, por supuesto, prerrogativa del animal humano, singular y soberano (WOLFE, 2013: 5-6), o de algún émulo suyo. Se trate de perros que narren o de perros accesorios que acompañen la narración, los canes parecen destinados a ser testimonios íntimos de "una vida más valiosa" (YELIN, 2017: 40), la de sus amos.

La animalidad perruna, así, se vuelve en muchos casos un objeto privilegiado de representación, idealizado y transformado en una metáfora del desamparo del sujeto, en un entorno descripto como "inhumano" (entendiendo por esto, precisamente, el producto más perfecto de todas las decisiones humanistas: condiciones materiales paupérrimas para la mayoría de las poblaciones, humanas o no, de la Tierra). Baste recordar la novela de 
John Berger, King: una historia de la calle (1998), donde el perro narrador nos abre las puertas de la percepción de la vida miserable de sus dueños, dos vagabundos, para que podamos ejercer a través de una lectura concienzuda y culposa nuestro burgués derecho a la crítica cultural de las condiciones materiales que, no obstante, perpetramos en nuestros hábitos de consumo más cotidianos (FUDGE, 2014: 51-52). O la película de Alejandro González Ińárritu Amores perros (2000) en que un perro, el Coffee, desencadena la serie de eventos que transforman en tragedias irreparables las vidas humanas allí narradas -salvo la del sicario que vive en la indigencia quien resulta redimido por la violencia asesina del perro. Tal como se evidencia en la traducción inglesa del título (Love's a bitch), el amor que aquí se refiere es el vínculo enfermo entre humanos, donde los perros no tienen más lugar que el de metáfora más o menos negativa del egoísmo, el dolor, la traición, la violencia, la soledad o la angustia humanas que producen las condiciones de vida del México finisecular. La feminización de la traducción del título, además, ancla despectivamente las figuras del perro y la puta, siempre serviles y siempre peligrosos.

En este trabajo ofreceré, a propósito del film La mujer de los perros (2015) de Laura Citarella y Verónica Linás y de la novela Perros héroes. Tratado sobre el futuro de América Latina visto a través de un hombre inmóvil y sus treinta Pastor Belga Malinois (2005) de Mario Bellatin, una posible contribución a los "estudios animales", y particularmente a los "estudios perrológicos"1, desde una perspectiva materialista posthumana, en la búsqueda de un pensamiento de la materialidad animal excedente de cualquier metáfora humana. De este modo, contextualizaré inicialmente el materialismo posthumano en el marco (parergon) de los Animal Studies para poder dar cuenta luego de algunos elementos del film que conj(et)uran modos no jerárquicos y físicos de cercanía inter-especies y de la novela que permiten pensar más allá de una consideración simbolista, una sintomatología perruna.

Antropo/androcentrismo:

un modo de producción hyle-bio-político

Los estudios animales han tenido un desarrollo importante desde fines del siglo pasado, pasando por las posturas jurídicas del Great Ape Proyect, los bienestaristas y los utilitaristas, hasta las fenomenologías de la heteroreferencialidad (BEKOFF, 2003; CAVALIERY \& SINGER, 1998) o el más auspicioso post-animalismo (STANESCU \& TWINE, 2012). La mirada que me interesa seguir aquí no es aquella que busca ampliar la cantera de los

1 Es la expresión que usa E. Marshall Thomas, 2003: 37. 
estudios de las "humanidades" (en una especie de proceso de visibilización y de ampliación de derechos a los excluidos, tal como ha sucedido en ciertas líneas de los estudios feministas, culturales o postcoloniales), que tiende a pensar siempre desde los presupuestos de un sujeto que conoce, con un instrumental binarista y que parece desatender toda dimensión individual no racional y toda dimensión colectiva material ${ }^{2}$. Por el contrario, intentaré pensar aquí la animalidad perruna a partir de sus aspectos potenciales, receptivos y afectivos, no efectuales ni funcionales, no ideales ni metafóricos, sino miméticos y literales, desde el umbral de los estudios críticos animales, es decir, desde dentro y fuera de ellos a la vez, dejándome guiar por el modo de existencia parergonal de los cánidos (y de los animales en general).

Brevemente, de acuerdo con la lectura derrideana de la ejemplificación estética kantiana, el parergon es lo que se ubica "contra, al lado y además del ergon, del trabajo hecho [...] afecta el interior de la operación y coopera con él desde cierto afuera [...] como un accesorio que uno está obligado a recibir en el borde, a bordo" (DERRIDA, 2001: 65). Por ello, puede considerarse que todo discurso sobre la distinción ontológica entre el hombre y los animales es un discurso del marco, un discurso que enmarca y separa volviendo interdependientes los elementos que reúne-como la "máquina antropológica" de dividir a los vivientes, jerarquizarlos y mantenerlos unidos en esa relación de la que hablara Agamben (2002). Los animales funcionan en ese discurso, que es inmunitario, como aquello "contra, al lado y además" del ergon, la tarea de lo humano, el imperativo de su permanente circunscripción. Los perros eyectados del sistema zootécnico (los restos), son, además, una pura argia: sin "vocación" específica (ya no labradores, nadadores, cazadores, guardianes, falderos, etc.), yacen sin utilidad productiva en las calles y los campos, cerca y lejos de los animales humanos, como veremos en el caso de La mujer de los perros. Parergonales, los animales son el a-bordo de la humanidad inestable, lo que la habita y la pone permanente en riesgo de naufragar; pero no sólo en un sentido lógico o epistemológico: no se trata aquí de un asunto exclusivamente abstracto o nominal, pues, como advierte Wolfe, "el problema del marco es un problema social y material" (2013: 6), un problema cuyas consecuencias no son exclusivamente simbólicas (es decir, no es sólo un discurso sacrificial que permite pensar la elevación de lo animal hacia lo humano a partir de cierto ritual). Sus consecuencias son, podríamos decir, hyle-bio-políticas.

Ciertamente, aunque los estudios biopolíticos hayan trabajado de modo exclusivo la cuestión de la "animalización" de lo humano, la distinción hombre/animales es la materia prima sobre la que se aplica el dispositivo que

2 Cfr. la crítica de John Sanbonmatsu a las perspectivas animalistas que tienen a la base una filosofía moral analítica en Sanbonmatsu, 2012: 49-58. 
transforma lo existente en "recurso natural", para garantizar la producción y la reproducción de la forma de existencia humana capitalista. El sistema de producción, disposición y distribución de lo existente está sostenido en una política que se hace cargo de la administración no sólo de la vida biológica de los individuos humanos - produciendo incesantemente una separación y una teleología entre la zoé y el bios- sino también de los demás vivientes y de la materia (hyle) -produciendo un "idealismo de la materia" que le proscribe toda agencia y la concibe como recurso inerte (LATOUR, 2015: 95, nota 6).

El especismo es el modo de producción capitalista y patriarcal (SANBONMATSU, 2012: 52) que justifica el dominio y la explotación de ciertos cuerpos (humanos o no) para asegurar la identidad del sujeto (varón, civilizado, burgués, heterosexual, etc.) su vida psíquica, política y social a través del flujo constante del capital ${ }^{3}$. Especismo y patriarcado van de la mano en el humanismo andrópico: la disponibilidad de los cuerpos de las mujeres permite no sólo la producción simbólica de la masculinidad (Segato, 2016) sino también su reproducción material. A su vez, de modo análogo, la disponibilidad de los cuerpos animales sostiene la supervivencia física y psíquica del varón: los "salvajes" afianzan la virilidad violenta del cazador, los "domésticos" soportan la ley del amo y los de "granja" le sirven de alimento (con especial mención de las hembras, a las que se les expropia sistemáticamente sus crías, sus huevos y su leche). Mujeres y animales son vidas desnudas: "cuerpos paupérrimos enajenados, que día tras día y en condiciones oprobiosas reproducen la carne animal que puebla el planeta: confinadas unas en el gallinero, el corral o el chiquero, otras en el hogar humano [o en la fábricas, las escuelas, las cárceles, los burdeles o las empresas] -con más o menos "bienestarismo" mediante- todas ellas son el cimiento sobre el cual se erige el gran edificio del modo actual de producción de las sociedades humanas occidentales y occidentalizadas" (referencia).

Entonces, porque sus vidas vulnerables no cuentan (BUTLER, 2006) en el cálculo del sujeto (da igual en qué dispositivo, si el soberano o el biopolítico, si homo juridicus o economicus 4 , siempre hominis -varón que ha llegado a la edad adulta), toda exploración imaginal de los modos de vinculación no simbólicos ni jerárquicos entre estas figuras puede resultar todavía interesante.

\footnotetext{
3 Con sus especificidades, desde Adorno y Horkheimer hasta Carol Adams, han explicado este vínculo entre mujer y animal y su situación de subordinación en el dominio de la producción y reproducción capitalista. Cfr. ADORNO \& HORKHEIMER, 1998: 291-299 y ADAMS, 2000.

4 Me refiero a la distinción foucaultiana entre el dispositivo de poder soberano y el biopolítico, entre el sujeto como sujeto de derecho, como categoría legal de persona y el sujeto de "decisiones individuales que son individuales y no transferibles" contra el que se erige el biopoder. Cfr. M. Foucault, 2000 y 2007. Cfr. también, WOLFE, 2013: 21-23.
} 
En la película de Laura Citarella y Verónica Llinás, la "cuestión animal” y la "cuestión de la mujer"5 se dan cita sin grandilocuencias para imaginar modos vinculares no representacionales y, por ello, no dependientes del elemento lingüístico hominizador. Lejos de la figuración metafórica que convierte a los perros en émulos de sus amos conflictuados, el cine -esa máquina de fantasía (LIPPIT, 2013: 120-121)- permite en este caso la proliferación de espectros animados que no guardan semejanzas con una entidad modélica sino que, como una jauría de perros (di)símiles ${ }^{6}$, sobreviven en una reproductibilidad ya sin orígenes.

Un cuento mínimo: la vida cotidiana a la intemperie de unos perros y una mujer en un entorno híbrido, marginal con respecto al campo y a la ciudad (parergonal), a lo largo de un año señalado en sus variaciones climáticas. La sinopsis de la película apela a las fórmulas negativas para aferrar la vida misteriosa de la Mujer: no habla, no maneja dinero, no tiene una historia... etc. -una retórica que reconocemos pariente de la conceptualización filosófica del "animal"

Una lectura literal del título de la película admite una primera disrupción: el posesivo que delimita una pertenencia de ella, la mujer, a ellos, los perros -que incluyen, a su vez, todo lo existente que los rodea: un Umwelt en el que, contrariamente al dictum heideggeriano, nadie parece aturdido, pero tampoco aburrido pues el "operador metafísico" que efectúa el pasaje de la "pobreza de mundo animal" a la construcción de un mundo humano yace inoperante (HEIDEGGER, 2007 y AGAMBEN, 2002) ${ }^{8}$. La mujer es de los perros, aunque la posesión, así enunciada, se indetermina en una desposesión. Esta lógica analógica y horizontal teje la trama sin interioridad del film: ella es como un perro y un perro es un perro, uno (singular) entre otros (cualquiera). Ella es "como" un perro: y esto es así no sólo desde la mirada andro/antropológica -aquí presentada por los adolescentes que la llaman la loca de los perros: ella, como sus amigos perros, es un cuerpo desechable y disponible para la ejercitación de la violencia, que ayuda a constituir sus virilidades en permanente construcción-sino también desde la mirada animal,

5 Acaso no resulte meramente casual, después de todo, que se trate de un proyecto que involucró a cinco mujeres: además de las directoras, las directoras de fotografía y de arte más una vestuarista.

6 Por no remitir directamente a la primera enunciación del problema de la mímesis y la relación jerárquica entre modelo y copia en el libro X de República, cfr. FOUCAULT, 2012: 58-71.

7 Es Derrida quien llamó la atención sobre el uso del abstracto "el animal" en el discurso filosófico (desde Descartes a Heidegger o Lacan) del que se ofrece una definición por sustracción: sin lenguaje, sin respuesta, sin sexualidad, sin mirada, etc. Cfr. DERRIDA, 2008, esp. Cap. II.

8 Agamben analiza la correlación estratégica entre el tedio humano (Langeweile) y el aturdimiento animal (Benommenheit) que aquí retomo. 
que la película explora con paciencia: nunca la escuchamos hablar, aunque sepamos que "puede" hacerlo (oímos, sí, jadeos y ladridos de los perros, así como el casi omnipresente canto de los pájaros y las escasas voces articuladas [logos] de la Médica, la Amiga o el Gaucho); vive como en un presente kairológico donde cada momento es una oportunidad arriesgada pero sin previsiones; vive, finalmente, una vida perruna, comunitaria y solidaria, de máximas cercanías físicas (duermen, cazan, pasean, recolectan y revuelven todos juntos) y máximas opacidades espirituales (no sabemos nunca lo que piensa y/o siente nadie).

Hay perros, además, seis u ocho de la jauría más otro, viejo y abandonado, que ella visita hasta que muere: todos recuerdan muy vagamente productos originales del mercado de la eugenesia zootécnica (uno agalgado con una cicatriz visible, uno tipo labrador blanco, uno negro lanudo, uno símil ovejero, uno pequeño, etc.), pero todos ociosos (argos) con respecto a la tarea (ergon) asignada a su (im)posible pedigree. Por lo demás, ellos no son un Otro que resalte por contraste la figura de la Mujer, ni hay sugeridos procesos de animalización (un especial "embrutecimiento" de la Mujer) o de humanización (una mascotización de los perros), hay un estar juntos más acá de toda socialidad humana o instintualidad salvaje. Habitan un medio que no es ni "mundo" (cultural) ni "naturaleza".

La película transcurre en el detalle de un amor sereno de caricias tenues, lamidas cuidadosas y solicitud recíproca que consiste sólo en un estar y un circular juntos en la banalidad de los quehaceres cotidianos. Es como si se nos mostrara la imagen, a la vez memorial y fantástica, del umbral en el que la vida desnuda se transforma, imperceptiblemente, por desobra o inoperancia del poder que la desnudó, en una forma-de-vida sin chauvinismo humanista ${ }^{9}$.

No se nos presenta un vínculo entrañable que nos haga llorar, porque la empatía entre ellos y para con el espectador no se sostiene en la identificación o en una transparencia mutua. Prevalece aquí un afecto opaco no íntimo, el encuentro misterioso de piel con pelo, de pata con mano y de boca con hocico: he aquí el misterio de la ausencia de todo misterio. Una vida que no se deja decir, misteriosa no porque custodie el secreto de un pasado de la Mujer que explique su situación actual, sino porque es la experiencia misma de lo que hay más acá del lenguaje: "una existencia serena e intransigentemente in-fantil" (AGAMBEN, 2010: 13) que, eventualmente, podría ser pensada como una contraconducta frente al disciplinamiento de los cuerpos y la materia, humanos o no, que impone el poder hyle-bio-político. No obstante, la apuesta de la película no parece ser la de una crítica cultural a las condiciones

\footnotetext{
9 Una lectura completamente diversa de la aquí propuesta puede leerse en I. Quintana, 2017: 122-138, aunque desde coordenadas teóricas similares a la aquí señaladas, Quintana piensa lo viviente desde la primacía de lo humano y de la decisión soberana de sustracción del propio cuerpo.
} 
de vida humana en los márgenes de la ciudad y el campo, pues no hay en ella nada parecido al moralismo burgués bienpensante horrorizado con el ubicuo cirujismo, aunque lo "muestre" en su absoluta concreción. Por el contrario, es la tenue afirmación de un modo de vida otro que resta, en su literalidad, sin definir.

\section{El símbolo perro en la literatura}

Como después en el cine, los perros fueron en la literatura los auxiliares perfectos para la construcción de la identidad personal humana. El desplazamiento del "imaginario humano hacia el mundo canino" para "indagar la condición humana" (SUBERCASEAUX, 2014, 33-62) es una constante que atraviesa la escritura de ficción desde sus comienzos. Pero los perros no han sido sólo metáforas, han sido, especialmente, símbolos: representaciones sensibles de una idea, signos comprensibles sólo por los animales humanos, sin semejanza ni contigüidad con aquello que evocan.

Casi como en la "vida real" donde fueron creados para la satisfacción irrestricta de las necesidades humanas, los perros literarios, generalmente "mascotas", han sido las pequeñas prostitutas (es decir, objetos de explotación física y emocional) del pensamiento antropocéntrico que busca justificar el lugar natural de los amos. Baste recordar aquí, a modo de ejemplo, la curiosísima Herr und Hund de Th. Mann en la que el narrador conoce con claridad meridiana las motivaciones de la conducta de su perro Bauschan, ese suplemento perfecto para su idílica huida del mundo. En esta novela se habla exclusivamente del perro, de sus características físicas, sus actos y sus reacciones frente a la indiscutida soberanía del amo: las especies viriles, se nos dice, tienden a venerar en el hombre de la casa a su señor absoluto. $Y$ ese rendido vasallaje es descripto como la perfecta compañía para una serena felicidad en un bucólico paisaje natural. El perdiguero alemán, algo impuro, se vuelve una especie de metáfora romántica de la olvidada pertenencia humana a la Naturaleza, entendida ésta a su vez como símbolo de estados subjetivos. Es decir, todo aquí reenvía de modo centrípeto al amo: el amor propio de un varón que refuerza su identidad en el reflejo admirable de su perro cazador. Leída en consonancia con las Betrachungen eines Unpolitischen de un año antes (1918), acaso podríamos decir que Herr und Hund es una recopilación de los lugares comunes de la Kultur alemana [el amor a la naturaleza, la libertad y la soledad, sostenidos en un vínculo afectivo, pero de absoluto dominio] frente al avance de la Zivilisation que amenaza con falsificar el auténtico ser del hombre (en su doble acepción de animal humano y varón) ${ }^{\mathbf{1 0}}$. Bauschan no es más que

10 No podría aquí reconstruir la compleja argumentación de las Consideraciones de un apolítico ni sus relaciones con la construcción intelectual de la germanidad en la Alemania de la primera guerra, me 
el símbolo de la virilidad moral de su amo, un apósito que encarna su costado natural, sensorial, salvaje, convenientemente domesticado. La novela es un relato melancólico que añora y perpetúa a la vez un incuestionado estado de cosas, en el que el señor dispone de un plato de sopa sobre la mesa y de un perro debajo de ella: memoria de un intemporal patriarcado especista [aquí aducido directamente al perro y llamado "instinto patriarcal"], que constituye a cada momento la especificidad de lo humano recortada sobre el trasfondo de una jerarquía de géneros.

¿Cuál es, entonces, la relación que se da entre el símbolo y la memoria? El símbolo (symbolon), "tablilla del recuerdo", es la evocación de un orden íntegro y total que, por ser ideal, se organiza en torno a la a cúspide de una taxonomía vertical de oposiciones binarias que custodia un pasado materialmente injustificable. El símbolo es un modo de gobierno y resolución de la inestable relación entre lo que hay y el pensamiento humano (MELANDRI, 2007). La memoria simbólica es la estrategia que oculta la dinámica de fuerzas opuestas de la que surge aquel sentido unívoco que se presenta como "recompuesto" (symballein). Dispositivo antropogenético por excelencia, el símbolo es la contraseña que el animal humano inventa para dominar la contingencia de lo existente e imponer orden (taxis) en el mundo. Una memoria simbólica es la operación de dación de sentido que se cristaliza y esconde el proceso del que nace, permitiendo referir lo acaecido a un centro (Dios, Naturaleza, Hombre) que garantice la continuidad del todo. El símbolo perro, por ello, tiene el valor táctico de asegurar la superioridad del hombre, de garantizar su seguridad ontológica (FRANKLIN, 1999: 85 y FUDGE, 2014: 32), de sostener la estabilidad doméstica y de naturalizar la dominación.

Con honrosas excepciones (por ejemplo, las kafkianas "Forschungen eines Hundes" o la vernácula Aventuras y desventuras de Casiperro del hambre, de Graciela Montes) incluso en las novelas donde la voz narradora es la voz de un perro -phoné que se articula rápidamente en un logos para reasegurar la relación jerárquica entre razón y sensación en la invención de un sujeto-, lo que se busca, es restaurar el reinado del humanismo en la sustitución del héroe novelesco ingenuo (YELIN, 2010: 93) que ha perdido completamente su lugar-en-el-mundo literario por falsedad ideológica. El perro, así, parece relegado a ser un tenue remedo de un discurso idealista, que lo transforma en el símbolo de la intimidad humana "más verdadera" y en una invitación al encierro en el hogar familiar y a la obediencia más timorata.

interesa dejar seńalada la búsqueda de una autenticidad de lo humano ampliada hacia elementos "naturales" como un nuevo modo de argumentación especista y patriarcal. 
Teniendo en cuenta esta literatura de perros, la novela de Mario Bellatin Perros héroes. Tratado sobre el futuro de América Latina visto a través de un hombre inmóvil y sus treinta Pastor Belga Malinois parece una feroz dentellada directo a la yugular del discurso antropocéntrico (relato idiota -idios- de un varón, europeo -o civilizado-, burgués, heterosexual...) que es necesario expulsar de la heterotopía que siempre fue América Latina. Leamos el comienzo:

Cerca del aeropuerto de la ciudad vive un hombre que, aparte de ser un hombre inmóvil -en otras palabras un hombre impedido de moverse-, es considerado uno de los mejores entrenadores de Pastor Belga Malinois del país. Comparte la casa con su madre, una hermana, su enfermero-entrenador y treinta Pastor Belga Malinois adiestrados para matar a cualquiera de un solo mordisco en la yugular. No se conocen las razones por las que cuando se ingresa en la habitación donde aquel hombre pasa los días recluido, algunos visitantes intuyen una atmósfera que guarda relación con lo que podría considerarse el futuro de América Latina. (BELLATIN, 2005: 309)

Esta novela, compuesta por una serie de 62 fragmentos cortos que relatan lo que podría ser la vida comunitaria de esos seres aquí presentados, no conjetura ninguna percepción perruna, no busca examinar los motivos "secretos" del comportamiento animal, ni establece nada parecido a la afectividad entre los animales humanos y los demás animales (treinta perros, un ave de cetrería y media docena de pericos de Australia): aquí los perros son el resultado más perfecto de la zootecnia que los inventó para aniquilar, asegurar, dominar, militarizar y atemorizar ${ }^{11}$. Ni figuras retóricas, ni símbolos, los perros son aquí sólo "síntomas"12 de un biopoder securitario que no se limita a la administración de la vida biológica de las poblaciones humanas (el cuerpo-enfermo del hombre inmóvil, los cuerpos femeninos siempre disponibles y los cuerpos animales "seleccionados" genéticamente como instrumentos de seguridad) y que logra neutralizar desde dentro los potenciales peligros para el mantenimiento del orden capitalista impuesto a las periferias (FOUCAULT, 2006). En la novela, el biopoder se muestra como zoopoder, o tal vez se evidencia la irrelevancia de la distinción bios/zoé en lo que respecta

11 El Pastor Belga Malinois ha sido seleccionado para ser un "perro de utilidad" apto para el adiestramiento. Se lo usa para detectar explosivos y drogas, para rastrear personas, como perro guardián, de defensa, de servicio o como pastor. Es la raza utilizada por el ejército norteamericano (Layka es la perra heroína que salvó a una unidad de combate durante un ataque en Afganistán en 2013, cfr. National Geographic, june 2014) y por la policía alemana.

12 En principio, quedémonos con la definición de la RAE: 1. manifestación reveladora de una enfermedad.

2. Seńal o indicio de que algo está sucediendo o por suceder. 
al control poblacional, pues todas las vidas humanas y no humanas, son aquí "vidas precarias", en la excepción (BUTLER, 2006 y AGAMBEN, 2003), pero funcionales a los dispositivos de seguridad para el manejo de las especies que los gobiernan. El poder absoluto del hombre inmóvil, que controla con gestos y sonidos todas las acciones de los perros y que digita los destinos de los animales humanos de la casa exigiéndoles atención constantemente, es una parodia del obsoleto poder territorial soberano de hacer morir y dejar vivir (el hombre inmóvil amenaza al enfermero-entrenador con matar a todos los perros si lo abandona, hace que los perros destrocen al ave de cetrería que vive encerrada en una caja, ordena, emite chillidos y sonidos inaudibles para que los perros aúllen constantemente, etc. $)^{13}$; poder que a su vez, es expuesto en su decadencia (su método de entrenamiento ha sido superado por unos collares que "lanzan discretos choques eléctricos para que los perros obedezcan de una manera más efectiva las órdenes de sus entrenadores") ${ }^{14}$. Aquí, por el contrario, un poder reticular y centrífugo organiza y transforma todos los cuerpos (incluso el inválido) en recursos de un sistema que parece naturalmente autorregulado. El perro, lejos del símbolo del sujeto, es un dispositivo de seguridad privada que se ofrece como arma de defensa estatal y para-estatal -el sueño de "la extrema derecha norteamericana" (BELLATIN, 2014).

En otra de las paredes hay un gran mapa de América Latina donde, con círculos rojos, están marcadas las ciudades en las que parece estar más desarrollada la crianza de Pastor Belga Malinois. Sólo a ciertos visitantes la presencia de este mapa los lleva a pensar en el fututo del continente. (BELLATIN, 2005: 323)

Estos perros en cuya selección, crianza y adiestramiento podría sostenerse el futuro de Latinoamérica, aparecen completamente desdibujados, sin rasgos singulares más que el de la nominación eventual de dos ejemplares que, por lo demás, son los únicos personajes que tienen un nombre propio dentro de la novela (Annubis, el preferido, y Shakura, la perra más vieja). Los animales humanos sólo son nombrados de acuerdo con su funcionalidad o

\footnotetext{
13 En una entrevista con Télam, Bellatin compara el poder cruel y rotundo del hombre inmóvil con el que detentan los "líderes poderosos de una incipiente nación africana sentados en un trono rodeados de cadáveres que sus órdenes fueron encargadas de producir". Poder soberano incipiente en esa zona del mundo, anticuado en los Estados Nación europeos donde nació. Cfr. BELLATIN, 2014.

14 "En los últimos tiempos, el prestigio del hombre inmóvil como entrenador de Pastor Belga Malinois ha decaído en forma notable. Quizá sea por el cambio en su carácter, que se hace cada vez más evidente. Cada día muestra una irritabilidad mayor no sólo con los perros sino, sobre todo con los dueńos de otros animales. El desprestigio puede haberse producido también porque las técnicas aprendidas del anterior enfermero-entrenador son ya obsoletas. El ring francés se moderniza con una rapidez asombrosa. Asimismo, se han inventado collares que lanzan discretos choques eléctricos para que los perros obedezcan de una manera más efectiva las órdenes de sus entrenadores. En sus actuales condiciones, el hombre inmóvil no tiene ya la posibilidad de adquirir ni estos collares ni los manuales que hay en circulación", BELLATIN, 2005: 327.
} 
ausencia de ella, como dijimos: el hombre inmóvil, el enfermero-entrenador, la madre, la hermana.

En los Pastor Belga Malinois, no obstante, se cifra la memoria material de un futuro-pasado americano, en la que los cómplices del estado de las cosas (la imposibilidad devenida necesaria, diría Foucault) son denunciados en la lógica misma de su funcionamiento y no en la "veracidad" de un documento. Bellatin construye un artefacto ${ }^{15}$ de memoria, sin apelar a lo que Nelly Richard (2007: 9) llama una "épica del metasignificado (Pueblo, Memoria, Identidad, Resistencia)" 16 , artefacto que desafía la tiranía de los significados estereotipados (el perro-símbolo, la opresión malvada de la víctima buena) y hace coincidir, caer conjunta y desordenadamente los existentes del mundo para traer a la superficie lo que se volvió inconsciente, natural, invisible en el orden impuesto.

Violencia y sordidez, extrañeza y antipatía, impiden aquí todo retorno al sentido en una bio/zoo-grafía y toda simbología cultural: pues ya no quedan más que existencias presentadas en la materialidad de su descomposición. Dice Graciela Speranza que parece decir Bellatin:

No hay crónica documental ni protocolo de la ficción realista [...] que pueda dar cuenta del sufrimiento, la opresión y la violencia del mundo próximo, ni traducir el vértigo de la experiencia inmediata. Más que representarlos, por lo tanto, se trata de encontrar una forma capaz de recuperar la extrańeza de lo vivido y el desconcierto de la visión fragmentada. (SPERANZA, 2012: 63)

La novela es acompañada por una serie de doce fotografías que Bellatin incorpora como improbable prueba del sustrato real de su historia. Un montaje tergiversante, una yuxtaposición que traza una "cartografía más imprecisa pero más certera de la violencia y la miseria endémica del continente" (SPERANZA, 2012: 71). Perros héroes fue escrita después de la primera visita de Bellatin al hombre inmóvil, tras responder a un anuncio sobre la venta de 20 cachorros Pastor Belga Malinois. Las fotografías fueron tomadas un año más tarde, cuando la novela ya estaba escrita, como buscando una relación posible entre lo fabulado y aquella experiencia que lo había generado. Se da entre fotografías y texto una relación oblicua e inestable, de yuxtaposición, ni jerárquica (explicativa) ni de correspondencia, pero, además, se da una relación temporal ambigua, trastocada, un vínculo futuro-pasado contranatura que se evidencia en la constatación futura (las fotos) de la invención

15 En la citada entrevista con Télam, Bellatin se entusiasma con la posibilidad de pensar la novela como un artefacto, entendiéndola menos como una "obra" que como un pretexto para que se disparen las interpretaciones.

16 El contexto de análisis, no relacionado con lo que aquí expongo, es el de la relación entre la Escena de Avanzada y la izquierda tradicional durante el Chile dictatorial. 
de un pasado (texto): el texto anterior corrobora las imágenes posteriores. "Recuento de un pasado y un futuro caracterizados por meras potencialidades y una falta de resolución”, dice Mónica Ríos, "escritura sintomática que evita la producción de conocimientos y dispone las coordenadas donde sólo la pregunta sin elocuencia es posible" (RÍOS, 2014: 94).

¿Qué tipo de ejercicio memorial se podría entrever en esta trama inmóvil? Si al símbolo perro correspondía una memoria que reenviaba a una historia como totalidad que debía custodiarse, el síntoma perro nos ofrece otro tipo de contigüidad fortuita, que no empuja a un más allá ideal, sino que amarra al más acá material en el que las cosas vienen a caer juntas, una al lado de la otra. En una hermosa fantasía etimológica, Paco Vidarte señala que:

Síntoma viene del griego "sin-pípto" [ind.: pet-], que significa, "caer juntamente", "coincidir". Designa así algo tan simple como que dos cosas vengan a caer juntas, una al lado de la otra, dos cosas coinciden, y ello puede o no suceder "propiciamente" (sin salirnos de esta familia); también lo que cae hacia adelante, lo que se precipita sintomáticamente que viene a ser lo mismo que fortuitamente. De síntoma procede también el término "asíntota", lo que se acerca mucho pero no coincide nunca. Y desecho, cadáver (ptóma), lo que cae. Y repetición. (VIDARTE, 2006)

Volviendo a la novela de Bellatin, aquí es la materia viva manipulada y transformada en recurso la que da cuenta de su historia, memoria de los territorios americanos que parecen haber renunciado a sus genealogías, pues el estado de cosas en el que habitan parece un designio divino sin tiempo, memoria de una materia viva y muerta, vuelta recurso colonial para la mejor fluidez de los bienes y aseguramiento del sistema. Perros héroes es el fotomontaje de un eterno presente en el borde del imperio, una máquina serial de mostrar sin desplazamientos metafóricos el umbral en el que lo humano no es un dato natural y la naturaleza no es una invención cultural o, mejor, en el que naturaleza, cultura, animal y humano, entran en la zona de indistinción que dio origen a su separación ${ }^{17}$.

Por ello, podría decirse que los animales humanos o los caninos que aquí comparecen no son símbolos, sino objetos arqueológicos, cuyas motivaciones internas son inalcanzables; objetos olvidados e ilegibles; restos fragmentarios e inutilizables para la construcción de "personajes" que den cohesión a una

17 Indistinción, ambigüedad que está presente desde el titulo mismo, pues ¿cuál es el sustantivo y cuál es el adjetivo? (cfr. RÍOS, 2014: 81). Al contrario de lo que sucede con Amores perros, aquí queda la duda de si se trata de la descripción sarcástica de la vida de los perros de guerra, a los que el capitalismo especista suele considerar "héroes"; o si por el contrario, se trata de una denigración del concepto de heroicidad a través de su asociación con los cánidos. En cualquier caso, esta contigüidad de palabras llaman la atención críticamente sobre los usos especistas de la figura del perro. 
historia narrada (cfr. CELATI, 1986: 217). La novela ofrece un experimento de arqueología sintomática que abandona la búsqueda de un archésustancial (el todo unificado prometido por el símbolo) para trazar el mapa de un campo atravesado por fuerzas contrarias (AGAMBEN, 2004: XXVII-XXIX) que no se resuelven en síntesis superadora alguna, pues son contingentes y accidentales. Los síntomas constatan una contigüidad aleatoria, pero no convencional (arbitraria), sino material: son ecos del acontecer, señales de un futuro que llegó hace rato.

\section{A modo de conclusión provisoria}

Este escrito ha querido ser una contribución a un pensamiento comunitario post-humanista, a través del análisis de dos manifestaciones artísticas latinoamericanas contemporáneas que parecen escapar a los principales lugares comunes de lo que hemos llamado capitalismo patriarcal y especista: una como mínima variación en torno a una forma-de-vida común no jerarquizante y otra como una sarcástica operación de exposición sintomática de las condiciones de vida (humanas y animales) en la frontera del imperio. Aunque con tonos diversos y a partir de gestos opuestos, ambas asumen la imposibilidad de una transparencia que no sea solapamiento idealista entre perros y humanos, para transformarla en la potencialidad de fantasear otros modos de estar juntos, en el caso del film, y de desmantelar los cimientos de la sólo aparentemente destinal vida desnuda a la que han sido arrojados, en el caso de la novela.

\section{Referencias bibliográficas}

ADAMS, Carol. The Sexual Politics of Meat. A Feminist-Vegetarian Critical Theory, New York/London: Continuum, 2000.

ADORNO, Theodor W. \& HORKHEIMER, Max. "Hombre y animal", en $L a$ dialéctica de la Ilustración, trad. J. J. Sánchez. Madrid: Trotta, 1998: 291-299.

AGAMBEN, Giorgio. "Archeologia di un' archeologia" en Melandri, Enzo: La linea e il circolo. Studio logico-filosofico sull' analogia. Macerata: Quodlibet, 2004, XI-XXXV.

AGAMBEN, Giorgio. "La ragazza indicibile". In: FERRANDO, Monica \& AGAMBEN, Giorgio: La ragazza indicibile. Mito e mistero di Kore. Milano: Mondadori, 2010: 7-60.

AGAMBEN, Giorgio. L'aperto. L’uomo e l'animale. Torino: Bollati Boringhieri, 2002. 
AGAMBEN, Giorgio. Stato di eccezione. Homo sacer II, 1, Torino: Bollati Boringhieri, 2003.

BEKOFF, Marc. Nosotros los animales, Madrid, Trotta, 2003.

BELLATIN, Mario. "Parece que lo que está en juego es el tema de la esclavitud animal”, entrevista en Télam, 15/11/2014. Disponible en: <http://www.telam. com.ar/notas/201411/85476-parece-que-lo-que-esta-en-juego-es-el-tema-de-laesclavitud-animal.html, última visita: 14/09/2017>.

BELLATIN, Mario. Obra reunida. México: Alfaguara, 2005.

BUTLER, Judith. Vida precaria. El poder del duelo y la violencia, trad. F. Rodríguez. Buenos Aires: Paidós, 2006.

CAVALIERI, Patrizia \& SINGER, Peter. El Proyecto "Gran Simio». La igualdad más allá de la humanidad, Madrid, Trotta, 1998.

CELATI, Gianni. "Il bazar archeologico", Finzioni occidentali: fabulazione, comicità e scrittura. Torino: Einaudi, 1986.

DERRIDA, Jacques. El animal que luego estoy si(gui)endo, trad. C. de Peretti y C. Rodríguez Maciel. Madrid: Trotta, 2008.

DERRIDA, Jacques. "Párergon”, en La verdad en pintura, trad. M. C. González y D. Scavino. Buenos Aires: Paidós, 2001: 27-154.

FOUCAULT, Michel: Defender la sociedad. Curso en el Collège de France 1976, trad. H. Pons. Buenos Aires: Fondo de Cultura Económica, 2000.

FOUCAULT, Michel. Esto no es una pipa. Ensayo sobre Magritte, trad. P. E. Rodríguez. Buenos Aires: Eterna Cadencia, 2012, pp. 58-71.

FOUCAULT, Michel. Las palabras y las cosas. Una arqueología de las ciencias humanas, Trad. E. C. Frost. Buenos Aires: Siglo XXI, 1984.

FOUCAULT, Michel. Nacimiento de la biopolitica. Curso en el Collège de France 1978-1979, trad. H. Pons. Buenos Aires: Fondo de Cultura Económica, 2007.

FOUCAULT, Michel. Seguridad, territorio y población. Curso en el Collège de France 1977-1978, trad. H. Pons. Buenos Aires: FCE, 2006.

FRANKLIN, Adrian. Animals and Modern Cultures: A Sociology of Human-Animal Relations in Modernity. London: Sage, 1999.

FUDGE, Erica. Pets, trad. A. Bixio. Buenos Aires: Paidós, 2014.

HEIDEGGER, Martin. Los conceptos fundamentales de metafísica. Mundo, finitud, soledad, trad. A. Ciria. Madrid: Alianza, 2007. 
LATOUR, Bruno. Cara a cara con el planeta. Una nueva mirada sobre el cambio climático alejada de las posiciones apocalípticas, trad. A. Dilon. Buenos Aires: Siglo XXI, 2015.

LIPPIT, Akira, M. "La muerte de un animal” trad. G. Di Iorio y A. Sorín. Instantes y Azares, escrituras nietzscheanas, Año XIII, $\mathrm{N}^{\circ} 13$ : "La cuestión de los animales en el pensar contemporáneo", primavera 2013: 111-145.

MANN, Thomas. Herr und Hund. Frankfurt am Main: S. Fischer Verlag, 1958. [Traducción castellana consultada: Señor y perro, trad. F. Payarais y Oliver Brachfeld. Barcelona: Plaza \&Janes, 1963].

MELANDRI Enzo. Contro il simbolico, Macerata, Quodlibet, 2007.

QUINTANA, Isabel. "Parcelas de vida: el arte y sus restos", $452^{\circ} \mathrm{F}$. Revista de Teoría de la Literatura y Literatura Comparada, N¹7: "Literatura, imágenes y políticas de la vida”, Barcelona: Universitat de Barcelona, 2017: 122-138.

RICHARD, Nelly. Fracturas de la memoria. Arte y pensamiento critico. Buenos Aires: Siglo XXI, 2007.

RÍOS, Mónica. "El ruido maniobra de lo imperceptible. Sobre Perros héroes de Mario Bellatin”, en Raggio Miranda, S. (coord.): Salón de anomalías. Diez Lecturas criticas acerca de la obra de Mario Bellatin. Lima: Ediciones Altazor, 2014, 79-98.

SANBONMATSU, John. "Una Teoria Critica per la liberazione della natura" intervista a a cura di M. Maurizi, Animal Studies, Anno 1, № 1: "Politique della Natura", Roma, Nova Logos, nov. 2012, pp. 49-58.

SEGATO, Rita. La guerra contra las mujeres. Buenos Aires: Tinta Limón/Traficantes de sueños, 2016.

SPERANZA, Graciela. "Mario Bellatin. «Perros héroes. Tratado sobre el futuro de América Latina visto a través de un hombre inmóvil y sus treinta Pastor Belga Malinois", Atlas portátil de América Latina. Arte y ficciones errantes. Barcelona: Anagrama, 2012: 60-71.

STANESCU, Vasile \& TWINE, Richard (eds.). Journal for Critical Animal Studies. New York, ICAS, Vol. 10 N 4, 2012.

SUBERCASEAUX, Bernardo. "Perros y literatura: condición humana y condición animal”, Revista Atenea (Concepción), N 509, I Sem. 2014: 33-62.

THOMAS, Elizabeth M. The Hidden Life of Dogs. London: Orion, 2003: 37.

VIDARTE, Paco. "Derridaladacan: contigüidades sintomáticas. Sobre el objeto pequeño j@cques”, conferencia pronunciada el 19 de octubre de 2006, en Buenos Aires, en el marco de las $\mathrm{V}$ Jornadas internacionales Nietzsche y I Jornadas internacionales Derrida. Disponible en <https://redaprenderycambiar.com.ar/ derrida/comentarios/derridalacan.htm>. (última visita: 15/09/2017). 
WOLFE, Cary. Before the Law. Humans and Other Animals in a Biopolitical Frame, Chicago/London: University of Chicago Press, 2013.

YELIN, Julieta. "El animal biográfico", $452^{\circ}$ F. Revista de Teoría de la Literatura y Literatura Comparada, №17: "Literatura, imágenes y políticas de la vida", Barcelona: Universitat de Barcelona, 2017: 40.

YELIN, Julieta. "La voz de su amo. De la biografía (y la autobiografía) animal”, Quimera, Revista de Literatura No 325, Barcelona: diciembre de 2010: 91-93.

Paula Fleisner é professora, Doutora em Filosofía pela Universidade de Buenos Aires e Pesquisadora Adjunta do Conselho Nacional de Investigaçóes (CONICET) da Argentina. É professora de Estética no Departamento de Filosofia da Universidade de Buenos Aires. É autora do livro La vida que viene. Estética y filosofía politica en el pensamiento de Giorgio Agamben (EUDEBA, 2015) e coordenadora do livro colectivo El situacionismo y sus derivados. Sobre las relaciones entre el arte y la politica en la estética contemporánea (Prometeo, 2015). Tem publicado artigos em revistas internacionais especializadas e participado de congressos, encontros e jornadas e conferências em diversos lugares de Argentina e América Latina. Faz parte de grupos de pesquisa sobre estética e filosofia contemporânea. Suas pesquisas atuais focam numa estética materialista pós-humana.

E-mail: pfleisner@gmail.com 